Document downloaded from:

http://hdl.handle.net/10251/58029

This paper must be cited as:

Elena Fito, SF.; Fraile, A.; García-Arena, F. (2014). Evolution and emergence of plant viruses. Advances in Virus Research. (88):161-191. doi:10.1016/B978-0-12-8000984.00003-9

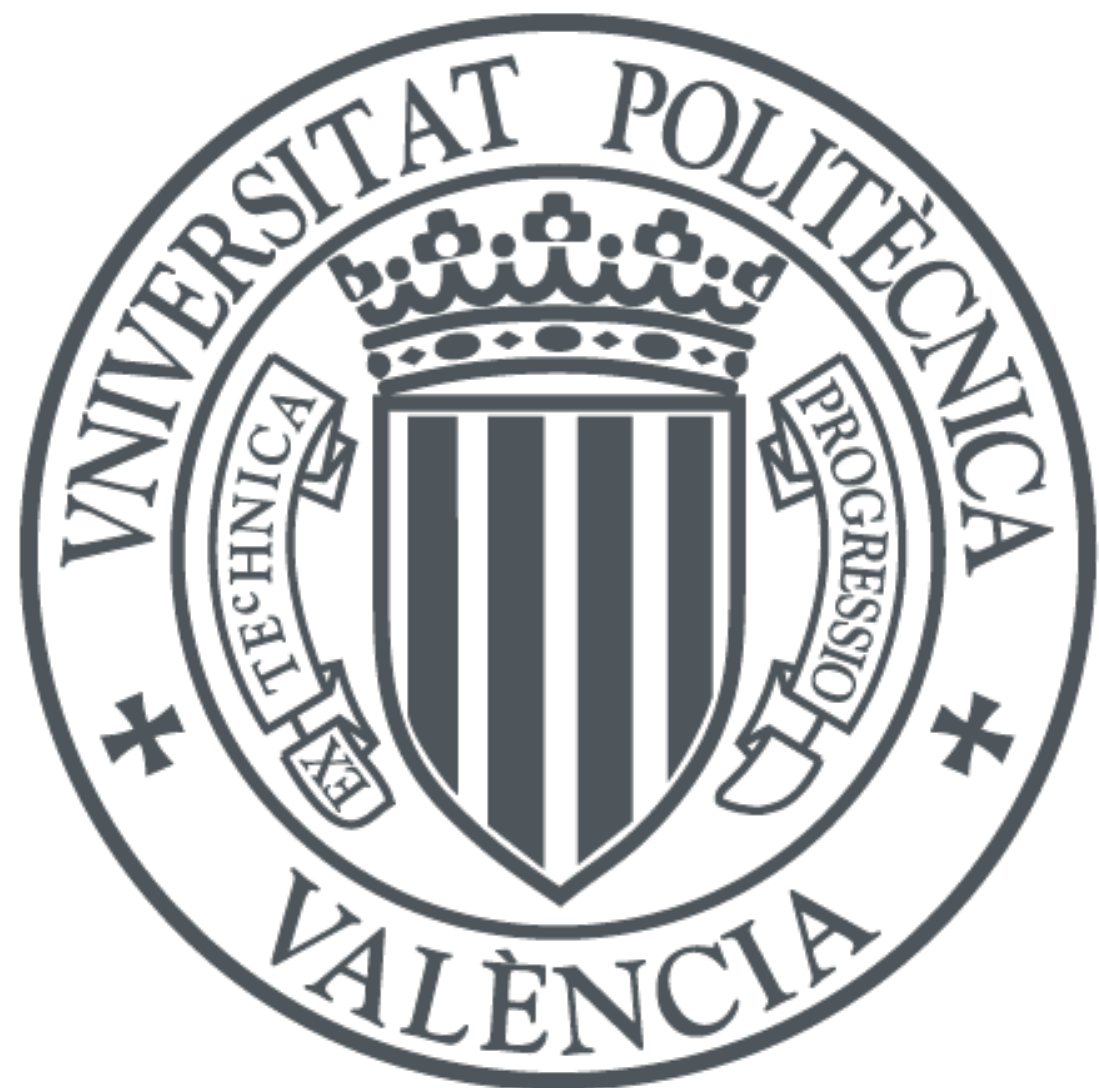

The final publication is available at

http://dx.doi.org/10.1016/B978-0-12-800098-4.00003-9

Copyright Elsevier (according to Zetoc)

Additional Information 


\title{
EVOLUTION AND EMERGENCE OF PLANT VIRUSES
}

\author{
Santiago F. Elena, ${ }^{*}{ }^{+}$Aurora Fraile, ${ }^{\#}$ and Fernando García-Arenal ${ }^{\# 1}$ \\ *Instituto de Biología Molecular y Celular de Plantas, CSIC-UPV, Campus UPV CPI 8E, \\ 46022 València, Spain \\ 'The Santa Fe Institute, Santa Fe NM 87501, USA \\ \#Centro de Biotecnología y Genómica de Plantas, UPM-INIA, and ETSI Agrónomos, \\ UPM, Campus de Montegancedo, Pozuelo de Alarcón, 28223 Madrid, Spain \\ ${ }^{1}$ Corresponding autor: fernando.garciaarenal@upm.es \\ Running title: Plant virus evolution and emergence \\ Key words: Virus evolution, virus emergence, virus ecology, host adaptation, across \\ host trade-offs, antagonistic pleiotropy, epistasis
}


1 Introduction

1.1 Phases on Virus Emergence

2 Phase I. Encounter of New Hosts or New Conditions

2.1 Ecological Factors Favoring Emergence

2.2 Host Jumps and Among Host Trade-offs

2.3 Antagonistic Pleiotropy as a Cause of Among-Host Trade-offs

3 Phase II. Virus Adaptation to the New Host

3.1 Factors Modulating Host Adaptation: Distribution of Mutational Effects and Epistasis.

3.2 Evasion, Suppression and Overcoming Host Defenses

3.3 Within-Host Evolutionary Dynamics: Genetic Drift and Metapopulation Dynamics

3.4 Mixed Infections and Among-Virus Interactions

4 Phase III. Long-Term Changes in Virus Epidemiology

4.1 Basic Reproductive Rate and Epidemics Dynamics

4.2 Host Competence and Transmission Rates

4.3 Virus Manipulation of Vector Life History

5 Conclusion: Gaps in Understanding Plant Virus Emergence

\section{ABSTRACT}

Viruses are common agents of plant infectious diseases. During last decades, worldwide agriculture production has been compromised by a series of epidemics caused by new viruses that spilled over from reservoir species or by new variants of classic viruses that show new pathogenic and epidemiological properties. Virus emergence has been generally associated with ecological change or with intensive agronomical practices. However, the complete picture is much more complex since the viral populations constantly evolve and adapt to their new hosts and vectors. The 
present review puts emergence of plant viruses into the framework of evolutionary ecology, genetics and epidemiology. We will stress that viral emergence begins with the stochastic transmission of preexisting genetic variants from the reservoir to the new host, whose fate depends on their fitness on each hosts, followed by adaptation to new hosts or vectors, and finalizing with an efficient epidemiological spread. 


\section{INTRODUCTION}

In the last two decades evidence has been growing on the increasing incidence of infectious diseases of humans, domestic and wild animals, and plants, due to the appearance of new pathogens or to the resurgence of previously described ones (Anderson et al. 2004; Woolhouse, 2002). This is at the basis of the interest in emerging pathogens, which can be defined as "the causative agents of infectious diseases whose incidence is increasing following its appearance in a new host population or whose incidence is increasing in an existing host population as a result of long-term changes in its underlying epidemiology“ (Woolhouse \& Dye, 2001), . Emergence is often accompanied by altered pathogenesis resulting in increased disease severity (Anderson et al., 2004; Cleaveland et al., 2007). Viruses are the major taxonomic group of emergent pathogens of humans, wildlife and plants, causing in all three host classes just under half of reported emergent diseases (Anderson et al., 2004; Dobson \& Foufopoulos, 2001; Taylor et al., 2001). The high socio-economic impact of emergent infectious diseases has motivated research efforts to disentangle the complex causes of pathogen emergence. The goal of this review is to analyze what is known about the drivers of plant virus emergence.

\subsection{Phases of Virus Emergence}

The causes favoring emergence are complex. Jones (2009) describes up to nine different scenarios favoring plant virus emergence, which can be summarized into four groups: i) changes in the host plant and/or virus ecology, ii) changes in the genetic composition of the host populations, iii) changes in the genetic composition of the virus population, and iv) in the case of vectored viruses, changes in the ecology and/or genetic composition of the vector. Emerging viruses have their origin in host species or populations in which they are well established, which play the role of reservoir hosts during emergence. Spread from the reservoir into a new environment (including the 
host as a key component of a parasite's environment), and establishing productive infections and effective between-host transmission mechanisms, are steps required for emergence to occur. Thus, factors driving emergence may be grouped according to a temporal schedule (Elena, 2011; Elena et al., 2011): in a first phase (Phase I), the virus must jump from the reservoir population to infect individuals of the same host species in a new ecological environment or of a new species. Host jumps, or pathogen spillovers, requires the contact between host populations, which may be favored by changes in the ecology of host, vectors or/and virus. In a second phase (Phase II), the virus must adapt to the new host or environment so that infections are productive enough to allow sustained transmission between individuals of the new host, i.e., infection in the new host or environment becomes independent of spillovers from the reservoir. Last, in a third phase (Phase III), the epidemiology of the virus must change to optimize between-host transmission in the new host population, what often requires adaptation to new vector species or new modes of transmission.

This review is organized according to these three phases. Knowledge on the ecological changes favoring between-host contacts resulting in spillovers, i.e., on the first step of emergence during Phase I, derives mostly from a posteriori reconstructions after emergence has occurred. This is also the case for changes in virus/vector ecology resulting in new epidemiological dynamics in the novel environment; experimental evidence on these issues is scarce. On the contrary, knowledge on virus evolvability to adapt to a new host, and on the factors that favor or constrain host adaptation, often derives from experimental evolution analyses specifically aimed at predicting what traits conditioning virus evolution will favor or hinder emergence, regardless that the experimental system is or not an emergent virus. 


\section{PHASE I. VIRUS ENCOUNTER OF NEW HOSTS OR NEW CONDITIONS}

\subsection{Ecological Factors Favoring Emergence}

According to the definition of emergence given above, viruses that emerge in one host necessarily have their origin in another host, or reservoir. Thus, ecological factors must favor the contact between the reservoir and the new host populations for a spillover to occur, as a first step eventually leading to emergence. It is considered that human activity associated with trade, agriculture or, more generally, with the anthropization of wild ecosystems, will favor host encounters and spillovers, what has been termed pathogen pollution (Anderson et al., 2004). Ecological factors associated to human activity and favoring virus emergence, can be split into two broad categories; simplification of ecosystems and increased connectivity between host and virus populations, including the introduction of new hosts, new viruses or new vectors into a geographical region.

\section{Ecosystem simplification}

The shrinkage of the area occupied by natural ecosystems in favor of the more simple agroecosystems has been considered for a long time to favor plant disease emergence: a classical concept in Plant Pathology states that ecological simplification associated with agriculture favors the appearance of new diseases in crops, as well as their incidence and severity, i.e., disease emergence. Specifically, three factors are considered to have a major role on disease emergence in agricultural systems: (i) the reduced species diversity of agroecosystems as compared with neighboring natural ecosystems, (ii) the reduced genetic diversity of crops as compared with wild populations of the same or related species, and (iii) the higher host density (Burdon \& Chilvers, 1982; Thresh, 1982). Support for these hypotheses is scant, and derives 
mostly from circumstantial or historical evidence (Stukenbrock \& McDonald, 2008). Current declines in biodiversity are at the root of a renewed interest on the relationship between biodiversity and disease risk (Keesing et al., 2010). Two major hypotheses, representing extremes of a continuum, relate biodiversity to disease risk. The "Amplification Effect" hypothesis predicts that diversity will be positively correlated with disease risk, as it will result in increased abundance of reservoirs for a focal host. The "Dilution Effect" hypothesis predicts a negative correlation between biodiversity and disease risk, as a reduction in diversity could result in an increased abundance of the focal host species facilitating disease transmission (Keesing et al., 2006). Hence, the effects of diversity on disease risk would be related to the host range of the pathogen.

A recent study has analyzed the relationship between biodiversity and disease risk in the wild pepper or chiltepin, Capsicum annuum var. glabriusculum, in Mexico (Pagán et al., 2012). This species has a local economical relevance, as its fruits are harvested in wild populations, plants are tolerated or favored in anthropic habitats, and, recently, its cultivation has started in small home gardens or family plots (GonzálezJara et al., 2011). Analyses of chiltepin populations growing in habitats with different levels of human intervention (wild, tolerated and cultivated populations) within a large geographic area in Mexico showed that increased human intervention was associated with a reduction of the genetic diversity of chiltepin populations (González-Jara et al., 2011), and with an increase of both virus infection risk and disease risk (Pagán et al., 2012). The main predictor of disease risk was the species diversity of the habitat, followed by the genetic diversity of the focal host when only populations in anthropic habitats were considered, results thus agreeing with the dilution effect hypothesis (Fig. 1). Interestingly, a decrease in biodiversity was associated to an increased risk of infection by two specialist viruses, the begomoviruses Pepper golden mosaic virus and Pepper huasteco yellow vein virus, while the risk of infection by the generalist virus Cucumber mosaic virus (CMV) was not affected by biodiversity (Pagán et al. 2012; Rodelo-Urrego et al., 2013). A further result of this work is that the fraction of 
begomovirus-infected plants that developed macroscopic symptoms was higher in cultivated than in wild chiltepin populations, indicating a higher severity of infections in agricultural environments whose causes have not been determined (Pagán et al. 2012; Rodelo-Urrego et al., 2013). The relationship between biodiversity and disease risk has also been analyzed in Cereal yellow dwarf virus (CYDV) and Barley yellow dwarf virus (BYDV). These luteoviruses infect many species of grasses, and have been the object of detailed experimental studies on their effects in wild grassland ecosystems in the west of the USA. Most published results are compatible with the amplification effect hypothesis, although the dilution effect hypothesis is also supported, depending on the composition of the species assemblage analyzed. Although generalists, CYDV and BYDV show partial host specialization, as they multiply to different levels in different grass species, which also differ in their ability to support the populations of the aphid vectors and in their competence as sources for virus transmission. These traits, together with the highly specific interaction between virus and aphid species for transmission, explain the effect of species composition on infection risk, and underline the complexities of virus ecology (Borer et al., 2009, 2010; Hall et al., 2010; Malmstrom et al., 2005a, b; Power \& Mitchell, 2004; Power et al., 2011).

Increased connectivity between virus and host populations

Human activities may result in the increased connectivity between host plant populations, and between virus and host populations, resulting in the emergence of new diseases. One way of establishing new connections between populations is the introduction of new host plant species, either cultivated or wild, and new viruses or their vectors, into geographical areas in which they were not present before. Host introductions are deliberate in the case of crops. However, the introduction of wild, potentially invasive, plants, and the introduction of viruses and vectors, is most often a side effect of translocation of plants and plant products, due to trade, or due to human movements. Introductions have been known for a long time to be factors in virus 
emergence; there are many well documented cases, and this knowledge is at the root of disease control measures based on regulations of trade in plant and plant products.

Host introductions have often resulted in the emergence of new viruses from wild reservoirs taxonomically related to the introduced host. Thus, Cacao swollen shoot virus (CSSV) emerged as an important pathogen of cacao in West Africa early in the XX century, shortly after this crop was introduced from America. Both the virus and its pseudococcid vector had their origin in lowland rain forest and savannah trees belonging to genera in the Malvaceae, as cacao (Theobroma cacao) itself (Posnette, 1981; Thresh, 1980). Similarly, Maize streak virus (MSV) emerged on maize, another American introduction, in Africa from local grasses in the Paniceae tribe of the Poaceae (Fargette et al., 2006; Martin et al., 2001). In other instances, the wild reservoir has not been identified, in spite of detailed surveys of the local flora; this is the case of African cassava mosaic virus and East African cassava mosaic virus, which are at the origin of the cassava mosaic disease pandemic occurring in Africa since the 1990s (Fargette et al., 2006). Host introductions may also result in virus emergence in wild plants, with consequences for ecosystem composition and dynamics as dramatic as in crops. A well-documented example concerns the introduced European wild oats Avena fatua in North America. The competitive advantage of wild oats over the perennial indigenous grasses in grasslands of western USA is due, at least in part, to the fact that wild oat is a more competent and tolerant host for CYDV and BYDV that the indigenous grasses, which are infected by spillovers from oats and suffer severely from infection (Power \& Mitchell, 2004).

The introduction of new viruses in a naïve area has also been linked to emergence in new hosts species or genotypes. Examples of viruses recently emerged in Europe include Pepino mosaic virus (PepMV), which spread as an important pathogen in tomato after 1999, from its probable origin in wild Solanum spp in Peru via infected seed (Gómez et al., 2012; Hanssen \& Thomma, 2010), Pepper mild mottle virus, introduced in the Mediterranean region with infected pepper seed from an 
unknown origin (Moury \& Verdin, 2012; Wetter et al., 1984) or Lettuce mosaic virus (LMV) strains that overcome $\mathrm{mol}$ resistance in lettuce, introduced from Chile again in infected seed (Krause-Sakate et al., 2002). Virus introduction may also have dramatic effects in the native flora, what has been particularly well documented in Australia (Jones, 2009). Thus, introduction of broad-range strains of Bean yellow mosaic virus, probably with infected gladiolus bulbs from Europe or Japan, has had a negative impact in native legumes in West Australia and in native orchids in East Australia (Gibbs et al., 2000; McKirdy et al., 1994; Webster et al., 2007). Other examples are discussed in Jones (2009). Last, vector introductions may be the cause of the emergence or re-emergence of viruses, as was the case for Tomato spotted wilt virus and Tomato yellow leaf curl virus after the introduction of their vectors, Frankliniella occidentalis and Bemisia tabaci biotype $\mathrm{B}$, respectively, in the Mediterranean basin (Díaz-Pendón et al., 2010; Hanssen \& Lapidot, 2012).

We should not finish this section without pointing that the coexistence of a virus and a new potential host in the same area does not necessarily lead to spillovers, which could be rendered improbable due to epidemiological factors. For instance, the population dynamics of CMV was broadly different in various wild hosts and crops in Spain, strongly suggesting that inter-host inoculum fluxes were restricted (Sacristán et al., 2004).

\subsection{Host Jumps and Among Host Trade-offs}

The host range for a virus is determined by several factors, some external to the virus, those that conform its epidemiology, and other intrinsic to the virus. It has been proposed that the host range of the vectors is the primary determinant for the host range of the virus, and that plant viruses are, generally speaking, generalists for hosts but specialists for vectors (Power \& Flecker, 2003). This hypothesis highlights the importance of vectors in the ecology of plant viruses and in their emergence, but it is clearly oversimplifying reality. Certainly, the biological fitness of an organism depends 
on the environments where it is measured, and the host is the fundamental environmental component for a parasite and, consequently, viral fitness shall vary across all its potential hosts. The differences in fitness among hosts are determinants of the host range and of the consequences of host jumps: a virus may have a high fitness in it(s) primary host(s) but a very low one in non-host species. Many emerging viruses mentioned in the previous section have a narrow host range and have been transmitted to a cultivated plant species from wild members of the same genera (e.g., LMV and PepMV) or family (e.g., CSSV and MSV), suggesting that a relationship may exist between the taxonomic proximity among hosts and the fitness of a specialist virus in all of them. Accordingly, PepMV adaptation to tomato (Solanum lycopersicum) does not seem to be associated to a trade-off in the closely related Solanum peruvianum or Solanum chilense, while a trade-off is apparent in the more distant Solanum muricatum (Moreno-Pérez et al., 2013).

These considerations drive to the concept of adaptive trade-offs among hosts: a parasite cannot simultaneously maximize its fitness in all alternative hosts, thus resulting in specialization, that is, in the adaptation to one or few related hosts in which fitness will be maximal. If adaptation to a host implies a fitness cost in alternative ones, this is at the basis of an adaptive trade-off among hosts. As a corollary to this principle, generalist parasites would evolve to a fitness value that may be maximized among hosts but that would be lower that the corresponding maxima on each individual host, thus precluding evolution to favor generalism (Fig. 2). In fact, the hypothesis that generalism pays a cost is supported by evidence that generalist viruses able of infecting a large number of hosts with equal efficiency seems not to be the norm. Thus, the prevalence of five generalist viruses in 21 wild plant species showed significant host-virus associations, indicating host selectivity as a strategy in these generalist viruses (Malpica et al., 2006). Also, host selectivity was shown for BYDV over different grass species (Power et al., 2011). These results suggest that generalist viruses may be not equally fit across all potential hosts, but that their capacity of multiplication and 
transmission varies among hosts, with possible adaptive trade-offs, as has been shown in some cases (Betancourt et al., 2011; Power et al., 2011; Sacristán et al., 2005). Therefore, from the perspective of emergence, a fundamental problem faced by a virus that jumps from its primary host to a new one is that, with a certain probability, mutations promoting adaptation to the new host would reduce its fitness in the primary one, generating a fitness trade-off (Fig. 2). The nature of these trade-offs and how they affect transmission across host species is an important research area.

Abundant experimental evidences showing the existence of fitness penalties associated to the capacity to infect a new host can be found in the plant virus literature. This cost is expressed as a reduction in fitness in the primary host (revised in Elena et al., 2009; García-Arenal \& Fraile, 2013) and it has its most likely origin in the different selective requirements imposed by each host (Fig. 2). Nonetheless, evidences also exist compatible with the alternative notion that the most restrictive host determines the fitness of a multi-host virus or even that no trade-off at all exists (Fig. 2). In this sense, the probability of evolving generalism depends on the frequency of transmission among heterologous hosts (Wilke et al., 2006): whenever transmission among host is infrequent, the viral population adapts to the most common one; by contrast, if heterologous transmission is frequent, the viral population behaves as if the fitness landscape was constant and equivalent to the average of each host. The behavior at intermediate transmission frequencies lies between these two extremes.

\subsection{Antagonistic Pleiotropy as a Cause of Among-Host Trade-offs}

What are the mechanistic causes of fitness trade-offs? Antagonistic pleiotropy is the simplest and most intuitive one (Whitlock, 1996): mutations that have a positive fitness effect on a given host are deleterious in an alternative one. A second mechanism that promotes trade-offs is the accumulation by genetic drift of neutral mutations in loci that are unnecessary in a host but essential in another one (Kawecki, 1994). Although both mechanisms imply host-dependent fitness effects, they are not equivalent: whereas 
natural selection is the only cause of trade-offs in the first mechanism, genetic drift is the cause for the second. Evidence for antagonistic pleiotropy has been reported for different virus species, and derives from the analyses of across-host effects of mutations introduced in viral genomes through manipulation of biologically active cDNA clones (e.g., Jenner et al., 2002; Liang et al., 2002; Moury \& Simon, 2011; Poulicard et al., 2010; Rico et al., 2006). Thus, evidence suggests that antagonistic pleiotropy is the most important mechanism, although certainly not the only one, generating acrosshosts trade-offs (Elena et al., 2009). Antagonistic pleiotropy emerges as an unavoidable consequence of small genome size and compaction of genetic information in viral genomes, with multiples cases of overlapping genes and multifunctional proteins that make unlikely to improve a function without jeopardizing another one.

\section{PHASE II. VIRUS ADAPTATION TO A NEW HOST OR NEW CONDITIONS}

\subsection{Factors Modulating Host Adaptation: Distribution of Mutational Effects and Epistasis}

The evolutionary fate of a viral population in a given host depends, ultimately, on the distribution of mutational fitness effects (DMFE), that is, the fraction of all possible mutations that are beneficial, neutral, deleterious, or lethal. In the case of a virus well adapted to a host and given its genome compactness, most mutations are expected to be either deleterious or lethal. Crucial for understanding the evolutionary destiny of viral populations, the DMFE on a genotype rarely remains constant across different hosts, and the contribution of each mutational category to overall fitness may vary depending on the degree of overlap between different environmental conditions (Martin \& Lenormand, 2006). This host-dependence of DMFE would clearly impact the probability of adaptation to new hosts. For example, if the change of host provides new 
opportunities, the fraction of beneficial mutations would increase, displacing the mean of the distribution towards higher values of making the variance larger (Fig. 3). Empirical analyses of DMFE for plant viruses are scarce, even for the primary host. Carrasco et al. (2007) characterized the DMFE for random nucleotide substitutions in the genome of Tobacco etch virus (TEV) in the primary host Nicotiana tabacum, finding that most mutations were lethal $(41 \%)$ or strongly deleterious $(36 \%)$, reducing fitness $41 \%$ on average. Twenty three per cent of mutations had no apparent fitness effect (neutral) and no mutation was beneficial. These results are in good agreement with those found for other RNA viruses (Domingo-Calap et al., 2009; Sanjuán et al., 2004a) and all characterize the genomes of RNA viruses as very sensitive to mutations, likely as a consequence of their high degree of compactness (Elena et al., 2006).

How does a change in host species affect the DMFE? To answer this question, Lalić et al. (2011) measured the fitness of a subset of the TEV single-nucleotide substitution mutants generated by Carrasco et al. (2007) across a panel of eight susceptible hosts that differed in their degree of taxonomic relatedness to tobacco, the primary host. The data obtained (Table 1) show that the host species wherein fitness is evaluated has a major effect on the DMFEs. The mean of the distribution moves towards smaller values (more deleterious effects) as the degree of genetic relatedness between the test host and the primary host decreases. Likewise, the distribution becomes more asymmetrical, with a larger fraction of mutations being beneficial as the new host is less and less related to the primary one. A detailed analysis of the data showed that the effect of a given mutation was dependent on the host wherein it was evaluated. Using terminology borrowed from quantitative genetics, this observation shows the existence of a significant genotype-by-environment component ( $G \times E)$ (Lalić et al., 2011). Moreover, this $G \times E$ component was explained in part by antagonistic pleiotropy, since most mutations change the sign of their effect depending on the host, and in part explained by a reduction in genetic variance for fitness among hosts (Lalić et al., 2011). The existence of this significant $G \times E$ component has important 
implications for viral emergence. First, it introduces a degree of uncertainty: knowing the effect of a mutation in a given host tells us very little, or nothing, about what would be its effect in an alternative host. Second, the likelihood of host specialization would be proportional to the extent by which the $G \times E$ component is generated by antagonistic pleiotropy. Third, the fact that a reduction in genetic variance for fitness also contributes significantly to generate a $G \times E$ component implies that genetic drift becomes important relative to natural selection during viral evolution, thus making the process of adaptation to a new host harder.

Given the high mutation rates characteristic of RNA viruses (Sanjuán et al., 2010), it is highly likely that genomes carry multiple mutations. The way these mutations interact to determine viral fitness is important, for instance, to know if certain genetic combinations will represent more likely evolutionary solutions than others. In terms of quantitative genetics, epistasis is equivalent to the existence of a genotypeby-genotype fitness component $(G \times G)$ : the fitness effect of a mutation depends on the genetic context wherein it appears. The intensity and type of epistasis shaping the genome of plant RNA viruses has only been explored, quite recently, for pairs of random mutations introduced in TEV genome (Lalić \& Elena, 2012a). Likewise to what has been described for other RNA viruses (e.g., Burch \& Chao, 2004; Sanjuán et al., 2004b), the average epistasis for TEV is also negative, that is, two deleterious mutations together are less pernicious that what would be expected from their individual effects. Echoing what we commented above to justify the large deleterious effect of individual mutations, the cause for this dominance of negative epistasis is also related with the lack of genetic redundancy characteristic of RNA genomes, with overlapping genes and multifunctional proteins (Elena et al., 2006).

Finally, to understand the genetics of viral emergence, it is also pivotal to determine whether epistasis is also host-dependent. Or put in quantitative genetics terms, to test whether a significant epistasis-by-host component $(G \times G \times E)$ exists. The 
information available on this issue is scarce and limited to a recent study by Lalic \& Elena (2012b) using TEV. This study shows that the sign of epistasis among pairs of random mutations depends on the degree of genetic relatedness between the primary host and the alternative ones. This observation suggests that selection more efficient promoting emergence as more distantly related the primary and the new hosts would be.

\subsection{Evasion, Suppression and Overcoming Host Defenses}

An important determinant of the fitness of a virus in a given host is its ability to overcome the defenses of the host. The mechanisms of resistance displayed by plants against viral infections have been reviewed in deep elsewhere (e.g., Carr et al., 2010; Moffet, 2009; Truniger \& Aranda, 2009). Overcoming plant resistance by changes in the pathogenicity of viral populations represents a specific and important case of emergence, with tremendous economical consequences since it jeopardizes the success and durability of resistance factors in crops as an anti-viral control strategy. The evolution of viral pathogenicity has also been recently reviewed (Fraile \& GarcíaArenal, 2010) and will not be developed in here. Nonetheless, we only want to highlight here that the viral genotypes overcoming resistances are, in general, less fit in susceptible plants than those viruses not overcoming the resistance, meaning that pathogenicity comes associated to a fitness penalty. In the few instances when this cost has been quantified it has been shown to be quite high [Fraile et al., 2011; see García-Arenal \& Fraile (2013) for the analysis of other published data]. This cost is, consequently, a specific example of fitness trade-off across hosts that is generated by antagonistic pleiotropy. This trade-off is of agronomic importance, since it makes difficult the fixation in the population of escape mutants, explaining why resistances against viruses have been more durable than those deployed against cellular pathogens (Fraile \& García-Arenal, 2010; García-Arenal \& McDonald, 2003). In recent years, attention has been drawn to understanding the factors that determine the 
overcoming of host resistances; identifying that virus' evolutionary potential and the number of required mutations to overcome the resistance are the two main factors (García-Arenal \& McDonald, 2003; Janzac et al., 2009). These studies are based in the analysis a posteriori of epidemiological data. The scarce experimental studies about overcoming resistances determined by major genes, dominant or recessive (Palloix et al., 2009), are affected by the difficulty of extrapolating laboratory fitness data to field conditions, since as we mentioned above, fitness depends on the conditions where it is evaluated.

Other studies have a different orientation, focusing in the analysis of virus potential to escape from defenses based on RNA silencing. With this aim, it has been evaluated the durability of the resistance against Turnip mosaic virus (TuMV) conferred by transgenic expression in Arabidopsis thaliana of artificial microRNAs (amiRs) specifically designed to be complementary to viral cistron encoding for the RNA silencing suppressor protein of this virus (HC-Pro). In a series of studies in which different TuMV lineages were evolved by serial passages in susceptible or partially resistant plants (De la Iglesia et al., 2012; Lafforgue et al., 2011; Martínez et al., 2012), it was found that the dynamics of overcoming resistance depended on the extent of protection conferred by the amiR, being it faster when the virus evolved in partially resistant plants than when it evolved in totally susceptible plants. Overcoming amiRmediated resistance was always associated to the presence of mutations at any of the 21 positions of the amiR target within HC-Pro. Another interesting observation was that the ancestral genotype of TuMV was detected, by Illumina ultra-deep sequencing, at a noticeable frequency in viral populations replicating in resistant plants (Martínez et al., 2012). This observation has implications for the use of this type of resistance, since it will favor the reversion to the wild type viral genotype in case escape mutations would have a fitness cost in susceptible plants.

We do not want to finish this section without mentioning recent studies that specifically simulated the emergence of a new virus, in this case the jump of TEV from 
it primary host, tobacco, to a new one, $A$. thaliana ecotype Ler-0. The results from this study delineate a picture in which TEV adaptation to the new host is concomitant with a change in the expression of host genes involved in stress response (including SAR and RNA silencing). These genes are significantly underexpressed to levels characteristic for non-infected plants (Agudelo-Romero et al., 2008b). These stress response genes were all overexpressed in plants infected with the ancestral TEV not adapted to $A$. thaliana (Agudelo-Romero et al., 2008a). Furthermore, when the virus adapted to ecotype Ler-0 was inoculated into other ecotypes, it was observed that the pattern of gene expression was correlated to the symptoms shown by infected plants: genes involved in responses to abiotic stresses and to building new tissues were overexpressed in those ecotypes showing mild symptoms and low levels of virus accumulation, whereas genes involved in defenses against pathogens were overexpressed in those ecotypes showing strong symptoms (Hillung et al., 2012). This results being confirmed with other viral systems, would help to conclude that natural selection would optimize viral fitness in a new host by making the virus invisible by the plant defense systems.

\subsection{Within-Host Evolutionary Dynamics: Genetic Drift and Metapopulation Dynamics}

The spatial structure within a plant of the viral population may affect the relative contribution of genetic drift and natural selection to evolution and, henceforth, the capacity to adapt to new hosts. The process of infection and colonization of plants by viruses was the subject of very detailed studies from the 1950 to the 1980 and it has been recently revived due to its evolutionary consequences (revised in García-Arenal \& Fraile, 2011). The fact that plant viruses miss of mechanisms that actively allow them to move across cell walls means that the colonization of their hosts must be symplastic. Consequently, plant viruses do not respond to a mass-action law, as it may be the case for bacteriophages infecting bacterial cultures growing in chemostats. The 
intercellular connections, the organization of tissues, the architecture of plants, and the connectivity between distal parts by the vascular system generates a highly structured environment wherein viral populations must replicate and evolve. In terms of population genetics, this means that the viral population replicating within an infected plant cannot be considered as a single, panmictic, population but as an ensemble of subpopulations, each one occupying distinct tissues or organs; that is, a metapopulation. Evidences for this within-plant structuration are abundant and gathered using distinct experimental approaches, RNA and DNA viruses, and herbaceous and tree hosts (Dietrich \& Maiss, 2003; González-Jara et al., 2009; Hall et al., 2001; Jridi et al., 2006). These spatial structures impose strongly restrictive conditions to the expansion of new beneficial mutations (those that eventually would increase the fitness of an emerging virus in the new host). Furthermore, spatial segregation reduces intracellular competition and, therefore, the efficiency of natural selection to optimize the average metapopulation fitness, independently of the magnitude of the beneficial effect conferred by a mutation, since the mutation would remain confined to a spatial region surrounded by less fit genotypes, as it has been recently proved for TEV (Zwart et al., 2011, 2012).

An interesting question is whether the segregation into subpopulations is governed by differences in viral fitness or, by contrast, is a purely stochastic process. The population genetics parameter used to quantify the impact of genetic drift in the structure of populations is the effective population size $\left(N_{e}\right)$. Answering the above questions, as well as to obtain good quantitative estimates of $N_{e}$ during the systemic colonization of a host, has attracted the attention of several groups along recent years. The experimental approaches to this problem were all based in infecting plants with a mixture of two or more genotypes of a virus and analyze the segregation of these genotypes on the different tissues or organs. The estimates of $N_{e}$ obtained so far vary between a few units (French \& Stenger, 2003; Sacristán et al., 2003) to few hundreds [Elena (2011) reanalyzing data from Li \& Roossinck (2004); Monsion et al., 2008]. 
Summarizing, $N_{e}$ varies widely among viruses and hosts. Whether these differences are relevant and a consequence of biological properties of each pathosystem, or simply experimental or analytical artifacts has to be solidly established. The relevant point here is that $N_{e}$ is always several orders of magnitude smaller than the number of viral genomes in the census of the population (e.g., in the order of $10^{10}-10^{12}$ per tobacco leaf for TMV; García-Arenal \& Fraile, 2011), suggesting that genetic drift must be important in the evolution of viral populations. We would like to make a final consideration about the spatial expansion of genetic variants when the multiplicity of infection is high: under such circumstances, complementation between genetic variants can reduce the rate of fixation of beneficial mutations (Frank, 2001). Whenever several viral genotypes are found within the same cell, the effective ploidy of the system is high, diluting the contribution of each locus to the phenotype and relaxing the effect of selection over each of them. A weaker selection implies more genetic diversity and the maintenance of deleterious variants in the viral population during longer periods of time. Indeed, in two different virus systems complementation efficiency has been estimated, showing the maintenance of these mutants at high frequency through transcomplementation (Fraile et al., 2008; Moreno et al., 1997). In such situations, evolving mechanisms of superinfection inhibition (Folimonova, 2012) would be beneficial for the virus in the long run, since these mechanisms would minimize complementation and accelerate the evolution of linked loci.

\subsection{Mixed Infections and Among-Virus Interactions}

We have just mentioned that coinfection and complementation among genetic variants carrying beneficial alleles and others carrying deleterious ones may slow down the rate of evolution. Nonetheless, during the early moments of Phase II, coinfection between an emerging virus and a different one already adapted to the new host may prove to be beneficial for the former. There are two relevant questions in this regard: (i) how frequent is that two viral species coinfect the same cells in the same plant? And (ii) do 
two viruses coinfecting the same plant share resources or, by contrast, occupy different niches?

Interspecific coinfections are a very common phenomenon and the plant virology literature contains a large number of references describing cases of coinfections. In an exhaustive analysis of the incidence of five viral species in 21 wild plant species, Malpica et al. (2006) found that the prevalence of certain viruses was not independent from the prevalence of other viruses; certain combinations appeared more frequently than expected by share chance. In an individual host, coinfection may have variable consequences, from the development of milder symptoms to their exacerbation (Hammond et al., 1999). Mixed infections also affect traits such as the host range (García-Cano et al., 2006; Guerini \& Murphy, 1999; Hacker \& Fowler, 2000), the rate of transmission (Wintermantel et al., 2008), cellular tropism (Moreno et al., 1997; Sánchez-Navarro et al., 2006), or viral accumulation (Martín \& Elena, 2009). Most studies focused in diseases caused by the synergy of two ssDNA or two ssRNA viruses, particularly of a potyvirus and other ssRNA virus. In many cases, the viral load of the non-potyvirus is increased, whereas that of the potyvirus remains unaltered, being this observation explained by the activity of the potyvirus HC-Pro protein as suppressor of RNA silencing (Dunoyer \& Voinnet, 2005). Nonetheless, these interactions not always result in a synergistic potentiation of symptoms (or in new symptoms), but the result depends from the particular combination of viral species, even with descriptions of a negative effect on the non-potyvirus accumulation (Kokkinos \& Clark, 2006).

In previous paragraphs we have provided evidences that two isolates of the same virus may exclude each other from a cell, creating spatially segregating distributions of genotypes with minimal overlap. At least in the case of potyviruses, the exclusion described by Dietrich \& Maiss (2003) was limited to variants of Plum pox virus (PPV), whereas potyviruses from different species did not exclude each other and were found infecting the same cells (Dietrich \& Maiss, 2003). Given that potyvirus 
species still show significant sequence similarities, interespecific coinfections between members of the same genus open the possibility for recombination and/or reassortment and, hence, for the origin of new viral species.

\section{PHASE III. LONG-TERM CHANGES IN VIRUS EPIDEMIOLOGY}

\subsection{Basic Reproductive Rate and Epidemics Dynamics}

Epidemics of emergent plant viral disease may be entirely sustained by spill-over from a reservoir. For example, Lettuce necrotic yellows virus (LNYV) emerged in lettuce crops in Australia in the 1950s from indigenous hosts in the Asteraceae. Emergence was due to the introduction of a new, highly competent host, Sonchus oleraceus, and a highly efficient vector, Hyperomyzus lactucae. Infection in lettuce results in a fast systemic necrosis, so that secondary infections are not relevant, and epidemics are due to transmission from the asymptomatic host S. oleraceus (Martin \& Randles, 1981). Another well-documented case concerns Mal de Rio Cuarto virus, a reovirus causing the major maize viral disease in Argentina since the 1980s, which is propagatively transmitted by delphacid vectors. Epidemics in maize are strictly monocyclic, and depend on the migration to the young maize plants of viruliferous vectors from wild grasses or winter grain crops such as wheat (Rodriguez Pardina et al., 1998). However, as was pointed out in the introductory section of this review, disease emergence usually involves deep epidemiological changes allowing the pathogen to establish cycles of secondary infection in the new host, after primary infection due to transmission from that host or from reservoirs.

Theory predicts that the epidemiological potential of a pathogen largely depends on its potential for transmission in the new host. Transmission potential may be assimilated to the disease's basic reproduction value, $R_{0}$, which represents the mean number of new infections per infected host in the susceptible host population. $R_{0}$ 
is a measure of the pathogen's fecundity, and it is considered as the best correlate for its fitness. Experimental determination of $R_{0}$ may be difficult, but $R_{0}$ is related to a second epidemiological parameter easier to estimate, the apparent infection rate of disease progress curves (DPC), $r$, as $r$ represents the number of secondary infections per infected host and per unit time. $R_{0}$ may be estimated from $r$ if the duration of the infectious period is known (Frank, 1996; Gibbs et al., 2010). An obvious condition for an epidemic to occur, is $R_{0}>1$. At the beginning of emergence, when the number of infected hosts is small, this condition will not be fulfilled, but considerations of stochasticity allow developing expressions that predict the probability of emergence (Gandon et al., 2012). $R_{0}$ is positively related to the transmission rate, $\beta$, and with the census size of the susceptible host population, and negatively to virulence and the rates of host mortality and recovery (Anderson \& May, 1982). Hence, during this phase of emergence, virus evolution should maximize $R_{0}$ by reducing virulence (see the LNYV case above) and/or increasing transmission rate.

\subsection{Host Competence and Transmission Rates}

Most epidemiological models assume that the between-host component of a pathogen's fitness is dependent on the within-host fitness component, i.e., that the between host transmission rate is positively correlated with the within-host multiplication rate. This relationship is also assumed in theoretical analyses of the epidemiology of vector-transmitted plant viruses (e.g., Jeger et al., 2006, 2011; Madden et al., 2000), which are the largest fraction of plant viruses. The transmission rate $\beta$ can be decomposed in the product of two parameters, the probability per unit time that a transmission event occurs $\left(\beta_{e}\right)$ and the probability of transmission per transmission event $\left(\beta_{p}\right)$ (Day, 2001; Escriu et al., 2003). For aphid-transmitted viruses, either persistently or non-persistently, it has been repeatedly shown that $\beta_{p}$ is positively correlated with virus accumulation in the source leaf within a range of accumulation values: transmission requires a threshold level of virus accumulation, and $\beta_{p}$ saturates 
at high virus accumulation (Escriu et al., 2000; Foxe \& Rochow, 1975; JiménezMartínez \& Bosque-Pérez 2004; Pirone \& Megahed, 1966). The relationship between transmission rate and within-host multiplication is highly relevant, and means that host adaptation during Phase II of emergence will have a direct consequence in the epidemiological changes during Phase III. However, this relationship may not hold for all types of virus transmission, as has been shown for contact-transmitted Tobacco mosaic virus (Sacristán et al., 2011).

Since $R_{0}$ is positively related to the size of the susceptible host population, it will be affected by host heterogeneity in resistance/susceptibility, i.e., heterogeneity in sustaining virus multiplication. Heterogeneity in susceptibility will result, thus, in heterogeneity in host competence, i.e., in how efficient is a host as a source for transmission (Cronin et al., 2010). The epidemiological consequences of host heterogeneity have been extensively modeled (Day et al., 2006; Lloyd-Smith et al., 2005, Yates et al., 2006), with the general conclusion that it will slow down emergence, but we are not aware of experimental tests of model predictions with plant viruses. Model analyses based on experimentally determined parameters, however, show that strain-specific differences in susceptibility and competence of two hosts of CMV determine the relative weight of primary (between-hosts) and secondary (within-host) transmissions for CMV epidemics and, according to the composition of the host population, may slow-down the emergence of highly virulent CMV strains (Betancourt et al., 2013). It should be mentioned that host competence also depends on host resistance or susceptibility to the insect vector, an important topic out of the scope of this review (Westwood \& Stevens, 2010).

The probability of transmission per transmission event, $\beta_{p}$, is mechanistically determined by specific interactions between viral proteins, such as the coat protein or the helper component, and poorly known vector factors, probably of a protein nature (Blanc \& Drucker, 2011). It has been repeatedly reported, in different viruses transmitted through different mechanisms, that there is genetic variation in virus 
transmission factors resulting in the variation of the diminished transmission rate, or in the loss of the ability for vector transmission (e.g., Atreya \& Pirone, 1993; Atreya et al., 1991; Bricault \& Perry, 2013; Perry \& Bricault, 2010; Perry \& Francki, 1992; Reddy \& Black, 1977; Uyeda et al., 1995). Genetic variation in transmission factors allows speculating that selection could occur on the virus population to optimize the molecular interactions resulting in vector transmission, so that transmission efficiency is increased. Thus, in Phase III of emergence, a process of virus adaptation to new vectors or new vector-host combinations could occur, similar to host adaptation during Phase II. It is also possible to envision the existence of trade-offs for adaptation to transmission to different vectors, or different transmission mechanisms, which would slow down adaptation to vectors. There is presently no information on this interesting topic, but the frequent loss of vector transmissibility in mechanically passaged viruses (Pirone \& Blanc, 1996; Reddy \& Black, 1977) suggests the existence of such tradeoffs.

We should again point that genetic drift during transmission could counter selection and thus slow down adaptation to a new host, or to a new vector and, ultimately, the increase of host competence. Several studies have shown that during aphid transmission severe population bottlenecks occur that may result in the loss of beneficial mutations that appeared during within-host multiplication. Different experimental estimates of such bottlenecks for non-persistently aphid-transmitted viruses indicate that they range from about 1 to 15 infectious particles per aphid and transmission event (Ali et al., 2006; Betancourt et al., 2008; Moury et al., 2007), again underscoring the relevance of genetic drift as a mechanism countering selection. Obviously, this strong bottleneck may not be relevant in field conditions if high density of aphid populations overcompensate it through the number of aphids involved in each transmission event, or through the increase in the probability of transmission events. The facilitating effect of high aphid population density in virus emergence has been 
shown for CMV both in homogeneous and heterogeneous host populations, through model analysis under realistic conditions (Betancourt et al., 2013; Escriu et al., 2003).

\subsection{Virus Manipulation of Vector Life History}

The second factor in the rate of between-host transmission, $\beta_{e}$, describing the probability that a transmission event occurs per unit time, depends on the density of the vector population, and on the vector's behavior (Madden et al., 2000). If both vector density and vector behavior would depend on the status, infected or not infected, of the host plant, they could be manipulated by the virus to increase transmission efficiency, and be the subject of selection. There are many reports showing that the fecundity of homopteran vectors of plant viruses is higher in plants infected by viruses, transmitted either persistently non-propagatively or non-persistently, than in non-infected plants, and higher vector performance results in an increase of their migration potential through the production of a higher proportion of winged individuals (reviewed in Fereres \& Moreno, 2009). This leads to a higher $\beta_{e}$. There are also reports to the contrary, showing that virus infection reduces vector fecundity, and these reports refer mostly to propagatively transmitted viruses that multiply in the insect vector (Donaldson \& Gratton, 2007). There is also evidence that virus infection may modify the attractiveness of plants to vectors. Enhanced attractiveness is due to altered visual cues and, particularly, to altered patterns of volatile compounds that act as olfactory cues. However, there are also reports that virus infection does not affect plant attraction to vectors. Result depend on the analyzed system and are often contradictory (Blanc \& Drucker, 2011; Fereres \& Moreno, 2009), which could be due to different methodologies used in the different studies or to reflect really the complexity of the three-fold relationship plant-virus-vector and its temporal variation. For instance, a recent report showed that squash plants infected by CMV have an altered pattern of volatiles that makes them more attractive to two aphid species that vector CMV. At the same time, infected plants are poorer hosts for these aphid species than non-infected 
ones, so that aphid fecundity is decreased and aphids abandon infected plants. This "deceitful attraction" would favor the transmission of the non-persistently transmitted CMV (Mauck et al., 2010). No doubt, the complex interactions of plants, viruses and vectors is an area in need of more research efforts in relation to virus evolution and emergence.

\section{CONCLUSION: GAP IN UNDERSTANDING PLANT VIRUS EMERGENCE}

As we hope this review has made clear, the emergence of plant virus diseases is not a new phenomenon, but although there is a renewed interest in the factors that favor emergence, and on their action, present knowledge is rather limited. New interest in virus emergence stems from the consensus that human alteration of the environment has an effect in the emergence of infectious diseases of plants, as is the case for diseases of humans, domestic animals and wild life, and from the increasing awareness on the unprecedented impact of human activity in ecosystem composition and dynamics. Three major factors related to human activities can be underscored as related to virus emergence. One is the quick loss of biodiversity, both as species richness and as genetic diversity of these species, of wild or anthropic ecosystems. Another one is the exceptional increase in the connectivity of host populations due to global trade in plant propagation material as well as in agricultural and forestry products, joint to a relaxation of regulation to control the spread of pests and pathogens. Last, global climatic change, and its resulting impact in the distribution range of hosts, vectors and viruses, is a reason for concern. How these factors may influence plant virus emergence has to be approached from the perspective of evolutionary ecology. The best understood aspect of plant virus emergence relates to the adaptation of viruses to new hosts, and to the evolutionary mechanisms that 
constrain or favor host adaptation, but evidence is still limited and derives from rather few experimental systems. Knowledge on the ecological factors that favor new encounters and host jumps derives mostly from a posteriori historical interpretations, and is in bad need of sound ecological experimentation. Last, the possibility that viruses evolve to increase their transmissibility in a new niche, through modifying the molecular mechanisms of virus-vector interaction or the vector's life history, is a virtually virgin region sparsely populated of highly suggestive reports. We hope that this review will stimulate the interest in the complexities of virus emergence.

\section{ACKNOWLEDGMENTS}

We acknowledge the financial support from the Spanish Dirección General de Investigación Científica y Técnica grants BFU2012-30805 (S.F.E.) and AGL200802458 (F.G.A.).

\section{REFERENCES}

Agudelo-Romero, P., Carbonell, P., De la Iglesia, F., Carrera, J., Rodrigo, G., Jaramillo, A., Pérez-Amador, M. A., \& Elena, S. F. (2008a). Changes in gene expression profile of Arabidopsis thaliana after infection with Tobacco etch virus. Virology Journal, 5, 92.

Agudelo-Romero, P., Carbonell, P., Pérez-Amador, M. A., \& Elena, S. F. (2008b). Virus adaptation by manipulation of host's gene expression. PLoS ONE, 3, e2397.

Ali, A., Li, H. Y., Schneider, W. L., Sherman, D. J., Gray, S., Smith, D., \& Roossinck, M. J. (2006). Analysis of genetic bottlenecks during horizontal transmission of Cucumber mosaic virus. Journal of Virology, 80, 8345-8350.

Anderson, R. M., \& May, R. M. (1982). Coevolution of hosts and parasites. Parasitology, 85, 411-426. 
Anderson, P. K., Cunningham, A. A., Patel, N. G., Morales, F. J., Epstein, P. R., \& Daszak, P. (2004). Emerging infectious diseases of plants: pathogen pollution, climate change and agrotechnology drivers. Trends in Ecology \& Evolution, 19, 535544.

Atreya, C. D., \& Pirone, T. P. (1993). Mutational analysis of the helper componentproteinase gene of a potyvirus: effects of amino acid substitutions, deletions, and gene replacement on virulence and aphid transmissibility. Proceedings of the National Academy of Sciences of the United States of America, 90, 11919-11923.

Atreya, P. L., Atreya, C. D, \& Pirone, T. P. (1991). Amino acid substitutions in the coat protein result in loss of insect transmissibility of a plant virus. Proceedings of the National Academy of Sciences of the United States of America, 88, 7887-7891.

Betancourt, M., Fereres, A., Fraile, A., \& García-Arenal, F. (2008). Estimation of the effective number of founders that initiate an infection after aphid transmission of a multipartite plant virus. Journal of Virology, 82, 12416-12421.

Betancourt, M., Fraile, A., \& García-Arenal, F. (2011). Cucumber mosaic virus satellite RNAs that induce similar symptoms in melon plants show large differences in fitness. Journal of General Virology, 92, 1930-1938.

Betancourt, M., Escriu, F., Fraile, A., \& García-Arenal, F. (2013). Virulence evolution of a generalist plant virus in a heterogeneous host system. Evolutonary Applications (in press)

Blanc, S., \& Drucker, M. (2011). Functions of virus and host factors during vectormediated transmission. In C. Caranta, M. A. Aranda, M. Tepfer, \& J. J. López-Moya (Eds.), Recent Advances in Plant Virology (pp. 103-120). United Kingdom: Caister Academic Press.

Borer, E. T., Mitchell, C. E., Power, A. G., \& Seabloom, E. W. (2009). Consumers indirectly increase infection risk in grassland food webs. Proceedings of the National Academy of Sciences of the United States of America, 106, 503-506. 
Borer, E. T., Seabloom, E. W., Mitchell, C. E., \& Power, A. G. (2010). Local context drives infection of grasses by vector-borne generalist viruses. Ecology Letters, 13, 810-818.

Bricault, C. A., \& Perry, K. L. (2013). Alteration of intersubunit acid-base pair interactions at the quasi-threefold axis of symmetry of Cucumber mosaic virus disrupts aphid vector transmission. Virology, 440, 160-170.

Burch, C. L., \& Chao, L. (2004). Epistasis and its relationship to canalization in the RNA virus $\phi 6$. Genetics, 167, 559-567.

Burdon, J. J., \& Chilvers, G. A. (1982). Host density as a factor in plant-disease ecology. Annual Review of Phytopathology, 20, 143-166.

Carr, J. P., Lewsey, M. G., \& Palukaitis, P. (2010). Signaling in induced resistance. Advances in Virus Research, 76, 57-121

Carrasco, P., de la Iglesia, F., \& Elena, S. F. (2007). Distribution of fitness and virulence effects caused by single-nucleotide substitutions in Tobacco etch virus. Journal of Virology, 81, 12979-12984.

Cleaveland, S., Haydon, D. T., \& Taylor, L. (2007). Overwiews of pathogen emergence: which pathogens emerge, when and why? Current Topics in Microbiology and Immunology, 315, 85-111.

Cronin, J. P., Welsh, M. E., Dekkers, M. G., Abercrombie, S. T., \& Mitchell, C. E. (2010). Host physiological phenotype explains pathogen reservoir potential. Ecology Letters, 13, 1221-1232.

Day, T. (2001). Parasite transmission modes and the evolution of virulence. Evolution, $55,2389-2400$

Day, T., Andre, J. B., \& Park, A. (2006). The evolutionary emergence of pandemic influenza. Proceeding of The Royal Society B, 273, 2945-2953.

De la Iglesia, F., Martínez, F., Hillung, J., Cuevas, J. M., Gerrish, P. J., Daròs, J. A., \& Elena, S. F. (2012). Luria-Delbrück estimation of Turnip mosaic virus mutation rate in vivo. Journal of Virology, 86, 3386-3388. 
Díaz-Pendon, J. A., Cañizares, M. C., Moriones, E., Rodríguez-Bejarano, E., Czosnek, H., \& Navas-Castillo, J. (2010). Tomato yellow leaf curl viruses: menage à trois between the virus complex, the plant and the whitefly vector. Molecular Plant Pathology, 11, 441-450.

Dietrich, C., \& Maiss, E. (2003). Fluorescent labelling reveals spatial separation of potyvirus populations in mixed infected Nicotiana bethamiana plants. Journal of General Virology, 84, 2871-2876.

Dobson, A., \& Foufopoulos, J. (2001). Emerging infectious pathogens of wildlife. Philosophical Transactions of the Royal Society B, 356, 1001-1012.

Domingo-Calap, P., Cuevas, J. M., \& Sanjuán, R. (2009). The fitness effects of random mutations in single-stranded DNA and RNA bacteriophages. PLoS Genetics, 5, e1000742.

Donaldson, J. R., \& Gratton, C. (2007). Antagonistic effects of soybean viruses on soybean aphid performance. Environmental Entomology, 36, 918-925.

Dunoyer, P., \& Voinnet, O. (2005). The complex interplay between plant viruses and host RNA silencing pathways. Current Opinion in Plant Biology, 8, 415-423.

Elena, S. F. (2011). Evolutionary constraints on emergence of plant RNA viruses. In C. Caranta, M. A. Aranda, M. Tepfer, \& J. J. López-Moya (Eds.), Recent Advances in Plant Virology (pp. 283-300). United Kingdom: Caister Academic Press.

Elena, S. F., Carrasco, P., Daròs, J. A., \& Sanjuán, R. (2006). Mechanisms of genetic robustness in RNA viruses. EMBO Reports, 7, 168-173.

Elena, S.F., Agudelo-Romero, P., \& Lalić, J. (2009). The evolution of viruses in multihost fitness landscapes. Open Virology Journal, 3, 1-6.

Elena, S. F., Bedhomme, S., Carrasco, P., Cuevas, J. M., de la Iglesia, F., Lafforgue, G., Lalić, J., Prosper, A., Tromas, N., \& Zwart, M. P. (2011). The evolutionary genetics of emerging plant RNA viruses. Molecular Plant-Microbe Interactions, 24, 287-293. 
Escriu, F., Perry, K. L., \& García-Arenal, F. (2000). Transmissibility of Cucumber mosaic virus by Aphis gossypii correlates with viral accumulation and is affected by the presence of its satellite RNA. Phytopathology, 90, 1068-1072.

Escriu, F., Fraile, A., \& García-Arenal, F. (2003). The evolution of virulence in a plant virus. Evolution, 57, 755-765.

Fargette, D., Konate, G., Fauquet, C., Muller, E., Peterschmitt, M., \& Thresh, J. M. (2006). Molecular ecology and emergence of tropical plant viruses. Annual Review of Phytopathology, 44, 235-260.

Fereres, A., \& Moreno, A. (2009). Behavioral aspects influencing plant virus transmission by homopteran insects. Virus Research, 141, 158-168.

Folimonova, S.Y. (2012). Superinfection exclusion is an active virus-controlled function that requires a specific viral protein. Journal of Virology, 86, 5554-5561.

Foxe, M. J., \& Rochow, W. F. (1975). Importance of virus source leaves in vector specificity of Barley yellow dwarf virus. Phytopathology, 65, 1124-1129.

Fraile, A., \& García-Arenal, F. (2010). The coevolution of plants and viruses: resistance and pathogenicity. Advances in Virus Research 76, 1-32.

Fraile, A., Sacristán, S., \& García-Arenal, F. (2008). A quantitative analysis of complementation of deleterious mutants in plant virus populations. Spanish Journal of Agricultural Research, 6, 195-200.

Fraile, A., Pagán, I., Anastasio, G., Saez, E., \& García-Arenal, F. (2011). Rapid genetic diversification and high fitness penalties associated with pathogenicity evolution in a plant virus. Molecular Biology and Evolution, 28, 1425-1437.

Frank, S. A. (1996). Models of parasite virulence. Quarterly Review of Biology, 71, 3778.

Frank, S. A. (2001). Multiplicity of infection and the evolution of hybrid incompatibilities in segmented viruses. Heredity, 87, 522-529. 
French, R., \& Stenger, D. C. (2003). Evolution of Wheat streak mosaic virus: dynamics of population growth within plants may explain limited variation. Annual Review of Phytopathology, 41, 199-214.

Gandon, S., Hochberg, M. E., Holt, R. D., \& Day, T. (2012). What limits the evolutionary emergence of pathogens? Philosophical Transactions of the Royal Society B, 368, 20120086.

García-Arenal, F., \& Fraile, A. (2011). Population dynamics and genetics of plant infection by viruses. In C. Caranta, M. A. Aranda, M. Tepfer, M., \& J. J. López-Moya, (Eds.), Recent Advances in Plant Virology (pp. 263-281). United Kingdom: Caister Academic Press.

García-Arenal, F., \& Fraile, A. (2013). Trade-offs in host-range evolution of plant viruses. Plant Pathology (in press).

García-Arenal, F., \& McDonald, B. A. (2003). An analysis of the durability of resistance to plant viruses. Phytopathology, 93, 941-952.

García-Cano, E., Resende, R. O., Fernández-Muñoz, R., \& Moriones, E. (2006). Synergistic interaction between Tomato chlorosis virus and Tomato spotted wilt virus results in breakdown of resistance in tomato. Phytopathology , 96, 1263-1269.

Gibbs, A.,Mackenzie, A., Blanchfield, A., Cross, P., Wilson, C., Kitajima, E., Nightingale, M., \& Clements, M. A. (2000). Viruses of orchids in Australia: their identification, biology and control. Australian Orchid Review, 65, 10-21.

Gibbs, A. J., Fargette, D., García-Arenal, F., \& Gibbs, M. J. (2010). Time - the emerging dimension of plant virus studies. Journal of General Virology, 91, 13-22.

Gómez, P., Sempere, R, N., \& Aranda, M. A. (2012). Pepino mosaic virus and Tomato torrado virus: two emerging viruses affecting tomato crops in the Mediterranean basin. Advances in Virus Research, 84, 505-532.

González-Jara, P., Fraile, A., Canto, T., \& García-Arenal, F. (2009). The multiplicity of infection of a plant virus varies during colonization of its eukaryotic host. Journal of Virology, 83, 7487-7494. 
González-Jara, P., Moreno-Letelier, A., Fraile, A., Piñero, D., \& García-Arenal, F. (2011). Impact of human management on the genetic variation of wild pepper, Capsicum annuum var. glabriusculum. PLoS ONE, 6, e28715.

Guerini, M. N., \& Murphy, J. F. (1999). Resistance of Capsicum annuum 'Avelar' to Pepper mottle potyvirus and alleviation of this resistance by co-infection with Cucumber mosaic cucumovirus are associated with virus movement. Journal of General Virology, 80, 2785-2792.

Hacker, D. L., \& Fowler, B. C. (2000). Complementation of the host range restriction of Southern cowpea mosaic virus in bean by Southern bean mosaic virus. Virology, $266,140-149$

Hall, J. S., French, R., Hein, G. L., Morris, T. J. Y., \& Stenger, D. C. (2001). Three distinct mechanisms facilitate genetic isolation of sympatric Wheat streak mosaic virus lineages. Virology, 282, 230-236.

Hall, G. S., Peters, J. S., Little, D. P., \& Power, A. G. (2010). Plant community diversity influences vector behavior and Barley yellow dwarf virus population structure. Plant Pathology, 59, 1152-1158.

Hammond, J., Lecoq, H., \& Raccah, B. (1999). Epidemiological risks from mixed virus infections and transgenic plants expressing viral genes. Advances in Virus Research, 54, 189-314.

Hanssen, I. M., \& Lapidot, M. (2012). Major tomato viruses in the Mediterranean basin. Advances in Virus Research, 84, 31-66.

Hanssen, I. M., \& Thomma, B. P. H. J. (2010). Pepino mosaic virus: a successful pathogen that rapidly evolved from emerging to endemic in tomato crops. Molecular Plant Pathology, 11, 179-189.

Hillung, J., Cuevas, J. M., \& Elena, S. F. (2012). Transcript profiling of different Arabidopsis thaliana ecotypes in response to Tobacco etch potyvirus infection. Frontiers in Microbiology, 3, 229. 
Janzac, B., Fabre, F., Palloix, A., \& Moury, B. (2009). Constraints on evolution of virus avirulence factors predict the durability of corresponding plant resistances. Molecular Plant Pathology, 10, 599-610.

Jeger, M. J., Seal, S. E., \& van den Bosch, F. (2006). Evolutionary epidemiology of plant virus disease. Advances in Virus Research, 67, 163-203.

Jeger, M. J., van den Bosch, F., \& Madden, L. V. (2011). Modelling virus- and hostlimitation in vectored plant disease epidemics. Virus Research, 159, 215-222.

Jenner, C. E., Wang, X., Ponz, F., \& Walsh, J. A. (2002). A fitness cost for Turnip mosaic virus to overcome host resistance. Virus Research, 86, 1-6.

Jiménez-Martínez, E. S., \& Bosque-Pérez, N. A. (2004). Variation in Barley yellow dwarf virus transmission efficiency by Rhopalosiphum padi (Homoptera :Aphididae) after acquisition from transgenic and nontransformed wheat genotypes. Journal of Economic Entomology, 97, 1790-1796.

Jones, R. A. C. (2009). Plant virus emergence and evolution: origins, new encounter scenarios, factors driving emergence, effects of changing world conditions, and prospects for control. Virus Research, 141, 113-130.

Jridi, C., Martin, J. F., Mareie-Jeanne, V., Labonne, G., \& Blanc, S. (2006). Distinct viral populations differentiate and evolve independently in a single perennial host plant. Journal of Virology, 80, 2349-2357.

Kawecki, T. J. (1994). Accumulation of deleterious mutations and the evolutionary cost of being a generalist. The American Naturalist, 144, 833-838.

Keesing, F., Holt, R. D., \& Ostfeld, R. S. (2006). Effects of species diversity on disease risk. Ecology Letters, 9, 485-498.

Keesing, F., Belden, L. K., Daszak, P., Dobson, A., Harvell, C. D., Holt, R. D., Hudson, P., Jolles, A., Jones, K. E., Mitchell, C. E., Myers, S. S., Bogich, T., \& Ostfeld, R. S. (2010). Impacts of biodiversity on the emergence and transmission of infectious diseases. Nature, 468, 647-652. 
Kokkinos, C. D., \& Clark, C. A. (2006). Interactions among Sweet potato chlorotic stunt virus and different potyviruses and potyvirus strains infecting sweet potato in the United States. Plant Disease, 90, 1347-1352.

Krause-Sakate, R., Le Gall, O., Fakhfakh, H., Peypelut, M., Marrakchi, M., Varveri, C., Pavan, M. A., Souche, S., Lot, H., Zerbini, F. M., \& Candresse, T. (2002). Molecular and biological characterization of Lettuce mosaic virus (LMV) isolates reveals a distinct and widespread type of resistance-breaking isolate: LMV-Most. Phytopathology, 92, 563-572.

Lafforgue, G., Martínez, F., Sardanyés, J., De la Iglesia, F., Niu, Q. W., Lin, S. S., Solé, R. V., Chua, N. H., Daròs, J. A., \& Elena, S. F. (2011). Tempo and mode of plant RNA virus escape from RNA interference-mediated resistance. Journal of Virology, $85,9686-9695$.

Lalić, J., \& Elena, S. F. (2012a). Magnitude and sign epistasis among deleterious mutations in a positive-sense plant RNA virus. Heredity, 109, 71-77.

Lalić J., \& Elena, S. F. (2012b). Epistasis between mutations is host-dependent for an RNA virus. Biology Letters, 9, 20120396.

Lalić, J., Cuevas, J. M., \& Elena, S. F. (2011). Effect of host species on the distribution of mutational fitness effects for an RNA virus. PLoS Genetics, 7, e1002378.

Li, H. Y., \& Roossinck, M. J. (2004). Genetic bottlenecks reduce population variation in an experimental RNA virus population. Journal of Virology, 78, 10582-10587.

Liang, X. Z., Lee, B. T. K., \& Wong, S. M. (2002). Covariation in the capsid protein of Hibiscus chlorotic ringspot virus induced by serial passaging in a host that restricts movement leads to avirulence in its systemic host. Journal of Virology, 76, 1232012324.

Lloyd-Smith, J. O., Schreiber, S. J., Knopp, P. E., \& Getz, W. M. (2005). Superspreading and the effect of individual variation on disease emergence. Nature, 438, 355-359. 
Madden, L. V., Jeger, M. J., \& van den Bosch, F. (2000). A theoretical assessment of the effects of vector-virus transmission mechanism on plant virus disease epidemics. Phytopathology, 90, 576-594.

Malmstrom, C. M., Hughes, C. C. Newton, L. A., \& Stoner, C.J. (2005a). Virus infection in remnant native bunchgrasses from invaded California grasslands. New Phytologist, 168, 217-230.

Malmstrom, C.M., McCullough, A.J., Johnson, H.A., Newton, L.A., \& Borer, E.T. (2005b). Invasive annual grasses indirectly increase virus incidence in California native perennial bunchgrasses. Oecologia, 145, 153-164.

Malpica, J. M., Sacristán, S., Fraile, A., \& García-Arenal, F. (2006). Association and host selectivity in multi-host pathogens. PLOS ONE, 1, e41.

Martin, S., \& Elena, S. F. (2009). Application of game theory to the interaction between plant viruses during mixed infections. Journal of General Virology, 90, 2815-2820.

Martin, G., \& Lenormand, T. (2006). The fitness effect of mutations across environments: a survey in light of fitness landscapes models. Evolution, 60, 24132427

Martin, D. K., \& Randles, J. W. (1981). Interrelationships between wild host plant and aphid vector in the epidemiology of lettuce necrotic yellows. In J. M. Thresh (Ed.), Pests, Pathogens and Vegetation (pp. 479-486). United Kingdom: Pitman.

Martin, D. P., Willment, J. A., Billharz, R., Velders, R., Odhiambo, B., Njuguna, J., James, D., \& Rybicki, E. P. (2001). Sequence diversity and virulence in Zea mays of Maize streak virus isolates. Virology, 288, 247-255.

Martínez, F., Lafforgue, G., Morelli, M. J., González-Candelas, F., Chua, N. H., Daròs, J. A., \& Elena, S. F. (2012). Ultradeep sequencing analysis of population dynamics of virus escape mutants in RNAi-mediated resistant plants. Molecular Biology and Evolution, 29, 3297-3307. 
Mauck, K. E., De Moraes, C. M., \& Mescher, M. C. (2010). Deceptive chemical signals induced by a plant virus attract insect vectors to inferior hosts. Proceedings of the National Academy of Sciences of the United States of America, 107, 3600-3605.

McKirdy, S. J., Coutts, B. A., \& Jones, R. A. C. (1994). Occurrence of Bean yellow mosaic virus in subterranean clover pastures and perennial native legumes. Australian Journal of Agricultural Research, 45,183-194.

Moffet, P. (2009). Mechanisms of recognition in dominant $R$ gene mediated resistance. Advances in Virus Research, 75, 1-33.

Monsion, B., Froissart, R., Michalakis, Y., \& Blanc, S. (2008). Large bottleneck size in Cauliflower mosaic virus populations during host plant colonization. PLoS Pathogens, 4, e1000174.

Moreno, I., Malpica, J. M., Rodríguez-Cerezo, E., \& García-Arenal, F. (1997). A mutation in Tomato aspermy cucumovirus that abolishes cell-to-cell movement is maintained to high levels in the viral RNA population by complementation. Journal of Virology, 71, 9157-9162.

Moreno-Pérez, M. G., Pagán, I., Aragón-Caballero, L., Cáceres, F., Fraile, A., \& GarcíaArenal, F. (2013). Reconstructing plant virus emergence: Pepino mosaic virus as a case study (submitted).

Moury, B., \& Simon, V. (2011). dN/dS-based methods detect positive selection linked to trade-offs between different fitness traits in the coat protein of Potato virus $Y$. Molecular Biology and Evolution, 28, 2707-2717.

Moury, B., \& Verdin, E. (2012). Viruses of pepper crops in the Mediterranean basin: a remarkable stasis. Advances in Virus Research, 84, 127-162.

Moury, B., Fabre, F., \& Senoussi, R. (2007). Estimation of the number of virus particles transmitted by an insect vector. Proceedings of the National Academy of Sciences of the United States of America, 104, 17891-17896.

Pagán, I., González-Jara, P., Moreno-Letelier, A., Rodelo-Urrego, M., Fraile, A., Piñero, D., \& García-Arenal, F. (2012). Effect of biodiversity changes in disease risk: 
exploring disease emergence in a plant-virus system. PLoS Pathogens, 8, e1002796.

Palloix, A., Ayme, V., \& Moury, B. (2009). Durability of plant major resistance genes to pathogens depends on the genetic background, experimental evidence and consequences for breeding strategies. New Phytologist, 183, 190-199.

Perry, K., \& Bricault, C. (2010). Alterations of capsid protein amino acid positions internal to virions of Cucumber mosaic virus disrupt nonpersistent virus transmission by aphids. Phytopathology, 100, S99-S100.

Perry, K. L., \& Francki, R. I. B. (1992). Insect-mediated transmission of mixed and reassorted cucumovirus genomic RNAs. Journal of General Virology, 73, 21052114.

Pirone, T. P., \& Blanc, S. (1996). Helper-dependent vector transmission of plant viruses. Annual Review of Phytopathology, 34, 227-247.

Pirone, T. P., \& Megahed, E. (1966). Aphid transmissibility of some purified viruses and viral RNAs. Virology, 30, 631-637.

Posnette, A.F. (1981). The role of wild hosts in cocoa swollen shoot disease. In J.M.Thresh (Ed.), Pest, Pathogens and Vegetation (pp. 71-78). United Kingdom: Pitman.

Poulicard, N., Pinel-Galzi, A., Hebrard, E., \& Fargette, D. (2010). Why Rice yellow mottle virus, a rapidly evolving RNA plant virus, is not efficient at breaking rymv1-2 resistance. Molecular Plant Pathology, 11, 145-154.

Power, A.G., \& Flecker, A.S. (2003). Virus specificity in disease systems: are species redundant? In P. Kareiva, \& S. A. Levin (Eds.), The importance of species (pp. 330-347). USA: Princeton University Press.

Power, A. G., \& Mitchell, C. E. (2004). Pathogen spillover in disease epidemics. American Naturalist, 164, S79-S89. 
Power, A. G., Borer, E. T., Hosseini, P., Mitchell, C. E., \& Seabloom, E. W. (2011). The community ecology of barley/cereal yellow dwarf viruses in Western US grasslands. Virus Research, 159, 95-100.

Reddy, D. V. R., \& Black, L. M. (1977). Isolation and replication of mutant populations of wound tumor virions lacking certain genome segments. Virology, 80, 336-346.

Rico, P., Ivars, P., Elena, S. F., \& Hernandez, C. (2006). Insights into the selective pressures restricting Pelargonium flower break virus genome variability: evidence for host adaptation. Journal of Virology, 80, 8124-8132.

Rodelo-Urrego, M., Pagán, I., González-Jara, P., Betancourt, M., Moreno-Letelier, A., Ayllón, M. A., Fraile, A., Piñero, D., \& García-Arenal, F. (2013). Landscape heterogeneity shapes host-parasite interactions and results in apparent plant-virus co-divergence. Molecular Ecology, 22, 2325-2340.

Rodriguez Pardina, P. E., Giménez Pecchi, M. P., Laguna, I. G., Dagoberto, E., \& Truol, G. (1998). Wheat: a new natural host for the Mal de Rio Cuarto virus in the endemic disease area, Río Cuarto, Córdoba province, Argentina. Plant Disease, 82, $149-152$.

Sacristán, S., Malpica, J. M., Fraile, A., \& García-Arenal, F. (2003). Estimation of population bottlenecks during systemic movement of Tobacco mosaic virus in tobacco plants. Journal of Virology, 77, 9906-9911.

Sacristán, S., Fraile, A., \& García-Arenal, F. (2004). Population dynamics of Cucumber mosaic virus in melon crops and in weeds in Central Spain. Phytopathology, 94, 992-998.

Sacristán, S., Fraile, A., Malpica, J. M., \& García-Arenal, F. (2005). An analysis of host adaptation and its relationship with virulence in Cucumber mosaic virus. Phytopathology, 95, 827-833.

Sacristan, S., Diaz, M., Fraile, A., \& García-Arenal, F. (2011). Contact transmission of Tobacco mosaic virus: a quantitative analysis of parameters relevant for virus evolution. Journal of Virology, 85, 4974-4981. 
Sánchez-Navarro, J. A., Herranz, M. C., \& Pallás, V. (2006). Cell-to-cell movement of Alfalfa mosaic virus can be mediated by the movement proteins of llar-, Bromo-, Cucumo-, Tobamo- and Comoviruses and does not require virion formation. Virology, 346, 66-73.

Sanjuán, R., Moya, A., \& Elena, S.F. (2004a). The distribution of fitness effects caused by single-nucleotide substitutions in an RNA virus. Proceedings of the National Academy of Sciences of the United States of America, 101, 8396-8401.

Sanjuán, R., Moya, A., \& Elena, S. F. (2004b). The contribution of epistasis to the architecture of fitness in an RNA virus. Proceedings of the National Academy of Sciences of the United States of America, 101, 15376-15379.

Sanjuán, R., Nebot, M. R., Chirico, N., Mansky, L. M., \& Belshaw, R. (2010). Viral mutation rates. Journal of Virology, 19, 9733-9748.

Stukenbrock, E. H., \& McDonald, B. A. (2008). The origins of plant pathogens in agroecosystems. Annual Review of Phytopathology, 46, 75-100.

Taylor, L., Latham, S. M., \& Woolhouse, M. E. (2001). Risk factors for human disease emergence Philosophical Transactions of Royal Society B, 356, 983-989.

Thresh, J. M. (1980). The origins and epidemiology of some important plant virus diseases. In T. H. Coaker (Ed.), Applied Virology, Vol. VII (pp. 1-65). United Kingdom: Academic Press.

Thresh, J. M. (1982). Cropping practices and virus spread. Annual Review of Phytopathology, 20, 193-218.

Truniger, V., \& Aranda, M. A. (2009). Recessive resistance to plant viruses. Advances in Virus Research, 75, 119-159.

Uyeda, I., Ando, Y., Murao, K., \& Kimura, I. (1995). High-resolution genome typing and genomic reassortment events of rice dwarf phytoreovirus. Virology, 212, 724-727.

Webster, C. G., Coutts, B. A., Jones, R. A. C., Jones, M. G. K., \& Wylie, S. J. (2007). Virus impact at the interface of an ancient ecosystem and a recent agroecosystem: 
studies on three legume-infecting potyviruses in the southwest Australian floristic region. Plant Pathology, 56, 729-742.

Westwood, J. H., \& Stevens, M. (2010). Resistance to aphid vectors of virus disease. Advances in Virus Research, 76, 179-210.

Wetter, C., Conti, M., Altschuh, D., Tabillion, R., \& Van Regenmortel, M. H. V. (1984). Pepper mild mottle virus, a tobamovirus infecting pepper cultivars in Sicily. Phytopathology, 74, 405-410.

Whitlock, M. C. (1996). The Red Queen beats the jack-of-all-trades: the limitations on the evolution of phenotypic plasticity and niche breadth. The American Naturalist, 148, S65-S77.

Wilke, C. O., Forster, R., \& Novella, I. S. (2006). Quasispecies in time-dependent environments. Current Topics in Microbiology and Immunology, 299, 33-50.

Wintermantel, W. M., Cortez, A. A., Anchieta, A. G., Gulati-Sakhuja, A., \& Hladky, L. L. (2008). Co-infection by two criniviruses alters accumulation of each virus in a hostspecific manner and influences efficiency of virus transmission. Phytopathology, 98, $1340-1345$.

Woolhouse, M. E. J. (2002). Population biology of emerging and re-emerging pathogens. Trends in Microbiology, 10, S3-S7.

Woolhouse, M. E. J., \& Dye, C. (2001). Population biology of emerging and reemerging pathogens. Preface. Philosophical Transactions of the Royal Society B, $356,981-982$.

Yates, A., Antia, R., \& Regoes, R. R. (2006). How do pathogen evolution and host heterogeneity interact in disease emergence? Proceedings of the Royal Society $B$, $273,3075-3083$.

Zwart, M. P., Daròs, J. A., \& Elena, S. F. (2011). One is enough: in vivo effective population size is dose-dependent for a plant RNA virus. PLoS Pathogens, 7, e1002122. 
Zwart, M. P., Daròs, J. A., \& Elena, S. F. (2012). Effects of Potyvirus effective population size in inoculated leaves on viral accumulation and the onset of symptoms. Journal of Virology, 86, 9737-9747. 
FIG. 1. Relationship between human management of habitat and disease risk in wild pepper (chiltepin) populations in Mexico. Disease risk is presented with three ecological factors: species richness of habitat, genetic diversity of host population, and density of host population. Data from Pagán et al. (2012).

FIG. 2. If a fitness trade-off exists, the figure illustrates the expected biological fitness for specialist and generalist viruses. Although both specialist viruses, represented by the blue and red bars, have high fitness on their respective primary hosts, each one has a very low fitness in the alternative host. The green bars illustrate the situation for a generalist virus, which has intermediate fitness values across all hosts. According to the trade-off illustrated in the figure, a specialist will always beat a generalist in its own host. If hosts alternate in space or time, the generalist virus may have an evolutionary advantage relative to the specialists.

FIG. 3. Possible effects of host switching in the distribution of mutational fitness effects. In all cases, the vertical dashed line indicates the average effect, whereas the vertical solid line indicates the null (neutral) effect. The surface under the curve that is at the left of the continuous line represents the fraction of beneficial mutations, whereas the surface at the right side of this line represents the fraction of deleterious mutations. The upper diagram shows the distribution for the primary host. The lower diagrams show two possible host effects: the left panel represents a change in the magnitude of the average effect without affecting the shape of the distribution; the right panel illustrates a change in the shape while retaining the same average effect. In both cases the fraction of mutations with beneficial effect increases. 
Table 1. Distribution of mutational effects for TEV across eight different hosts that differ in their taxonomic relationship

\begin{tabular}{lcccc}
\hline \multicolumn{1}{c}{ Host species } & Lethals & Deleterious & Neutrals & Beneficials \\
\hline Nicotiana tabacum ${ }^{2}$ & 0 & 30 & 70 & 0 \\
Nicotiana benthamiana & 0 & 50 & 50 & 0 \\
Datura stramonium & 10 & 75 & 15 & 0 \\
Capsicum annuum & 0 & 0 & 45 & 55 \\
Solanum lycopersicum & 40 & 0 & 10 & 50 \\
Helianthus annuus & 0 & 0 & 75 & 25 \\
Gomphrena globosa & 0 & 0 & 85 & 15 \\
Spinacea oleracea & 0 & 0 & 85 & 15 \\
\hline
\end{tabular}

${ }^{1}$ Values are expressed as percentages

${ }^{2}$ Values correspond to the subset of mutations used by Lalić et al. (2011) and not to the entire collection described in Carrasco et al. (2007) 


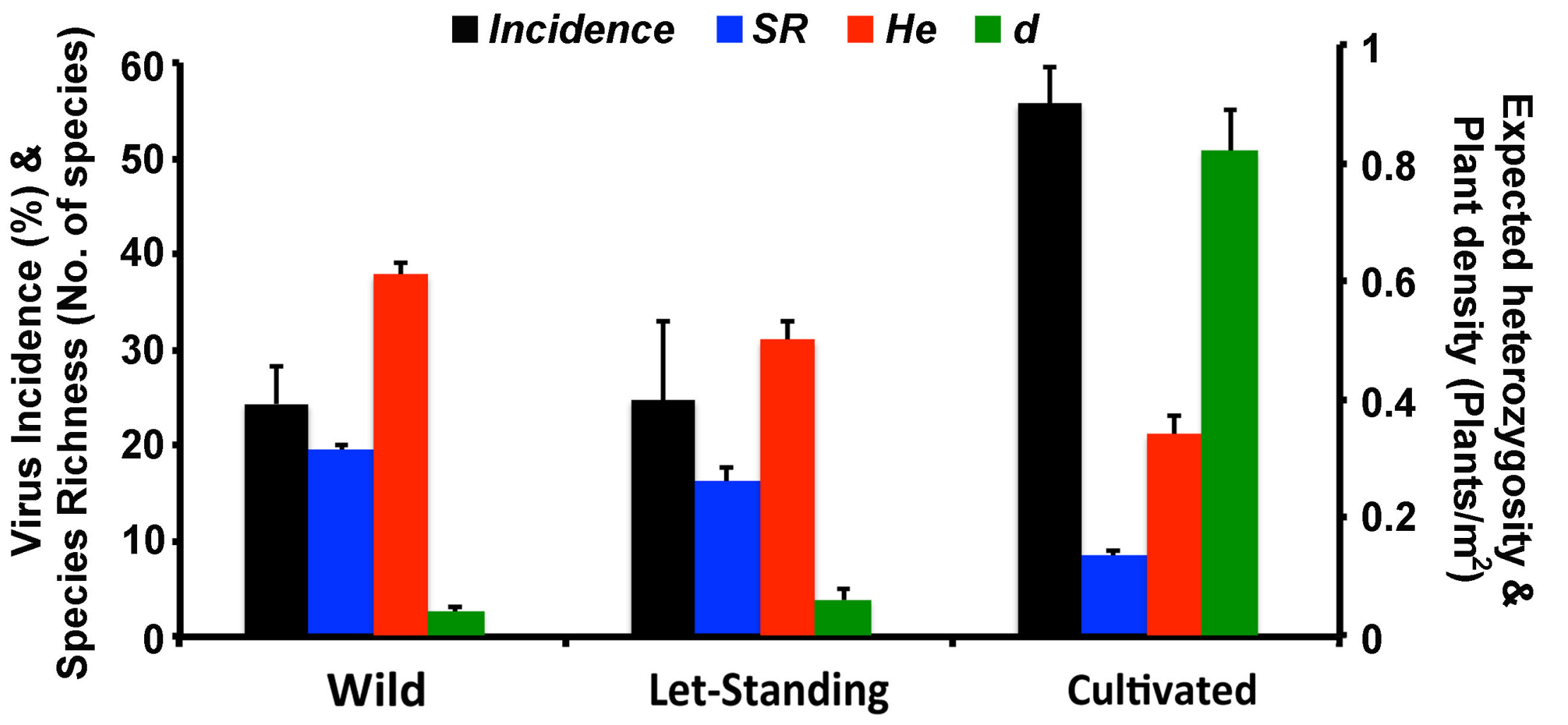

Level of human management 


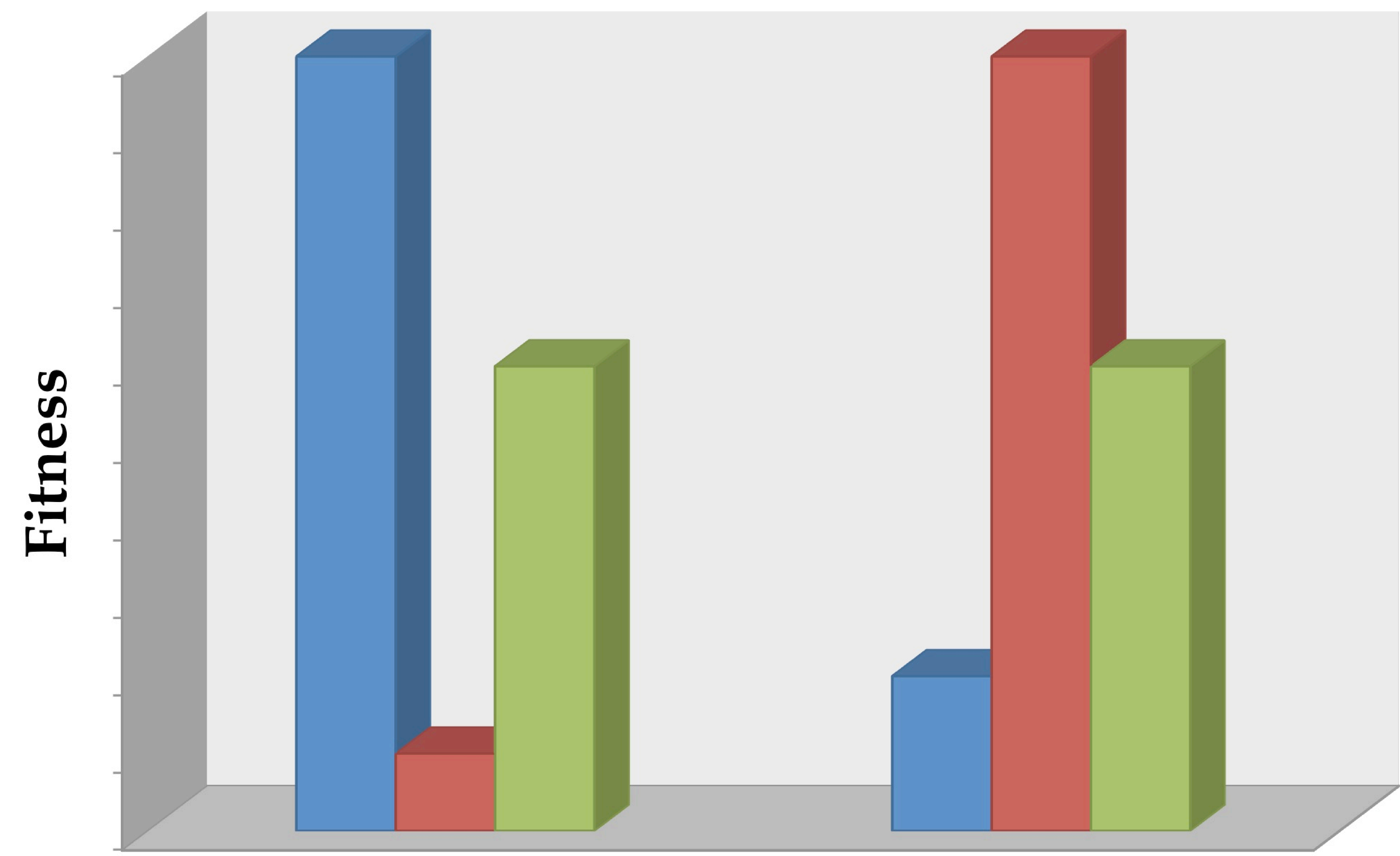

$\square$ Host A specialist

$\square$ Host B specialist

$\square$ generalist virus

Host A

Host B 


\section{Reservoir host}

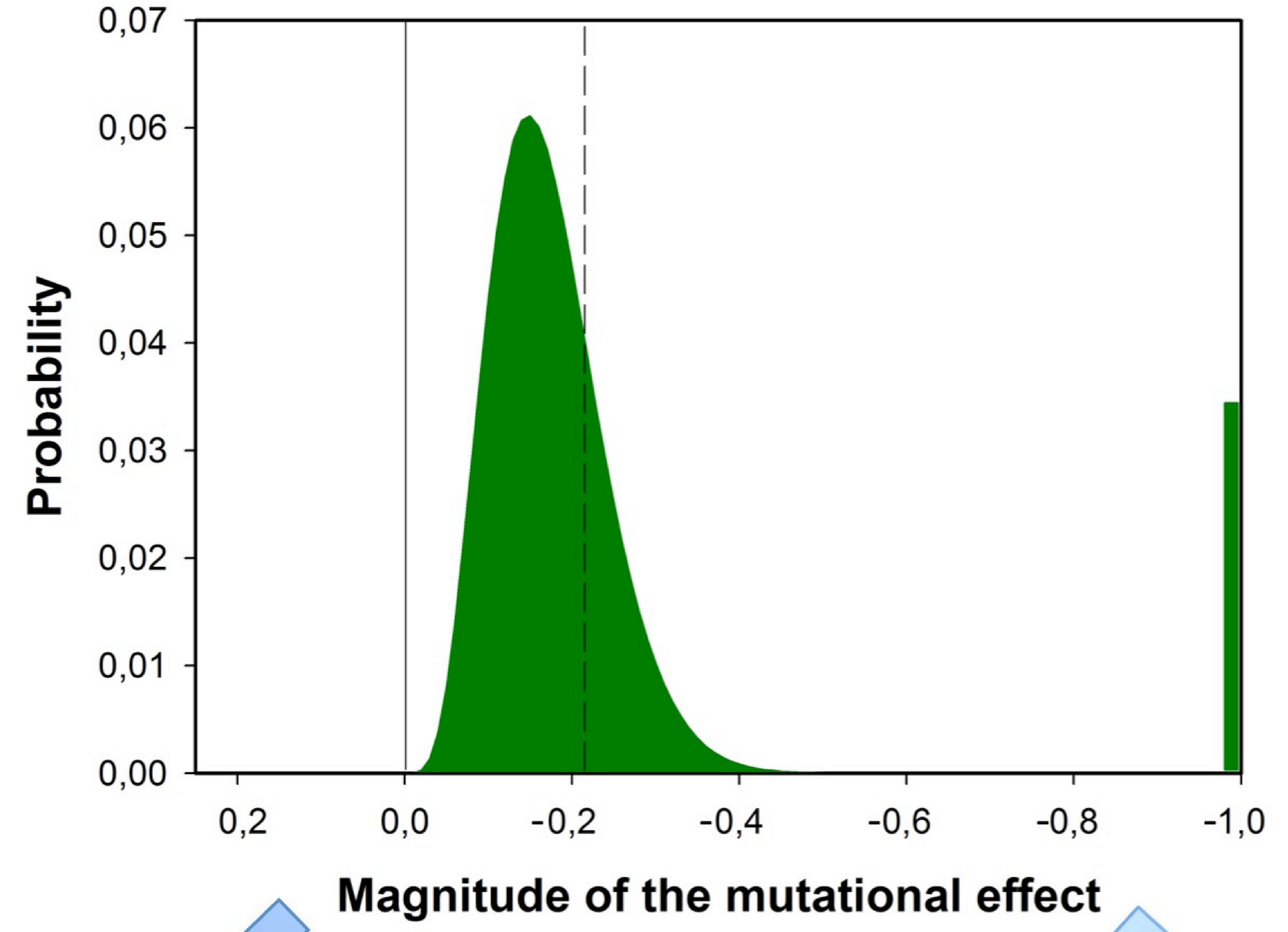

Change in mean, no variation in shape

No change in mean, change in shape

New host
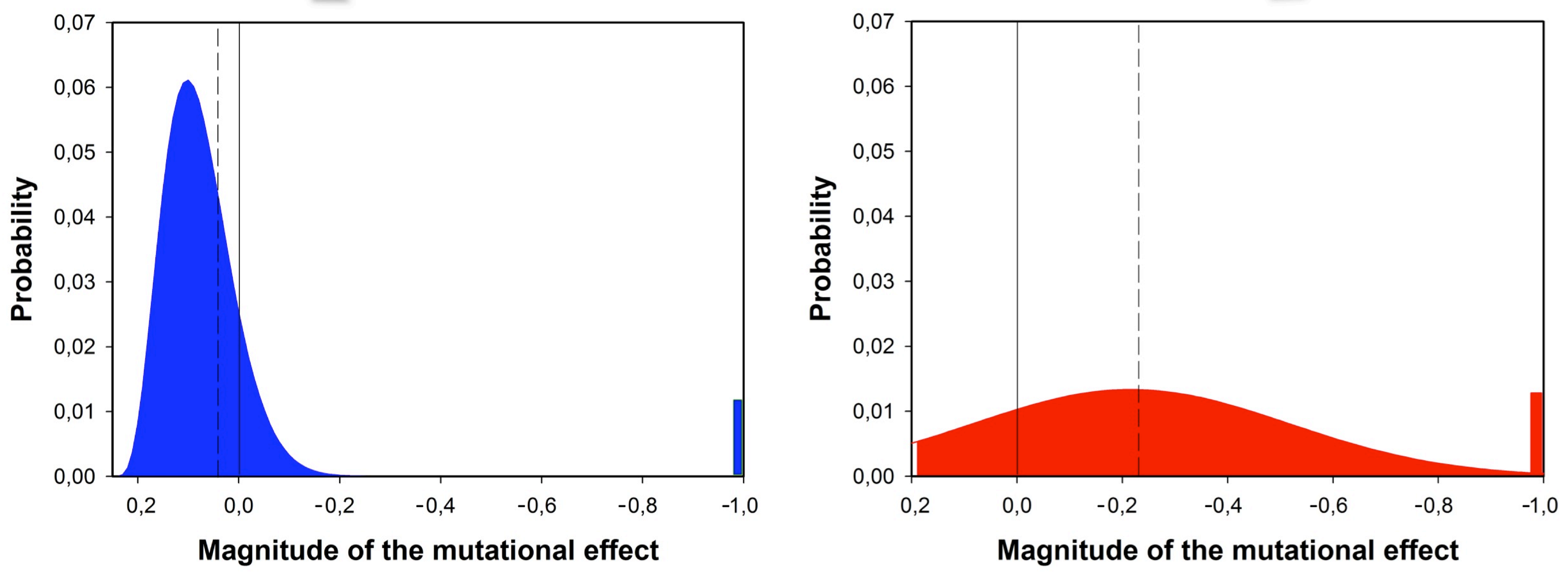